Original article

\title{
Age at first marriage and fertility in developing countries: A meta analytical view of 15 Demographic and Health Surveys
}

\author{
Md. Akhtarul Islam*, Abdur Rahman \\ Statistics Discipline, Khulna University, Khulna, 9208, Bangladesh
}

\section{A R T I C L E I N F O}

\section{Keywords:}

Age at first marriage

Fertility

per capita health expenditure

Developing countries and meta

Analysis

\begin{abstract}
A B S T R A C T
Background: Adolescent and early marriage increase the marriage duration which ultimately can boost the number of ever born children. On the other hand, when age at first marriage is too high there is a chance to birth complicity. In this study, the researcher has taken an attempt to investigate the structure of the relationship between female age at first marriage and fertility and find out a more precise estimate of the factor on fertility in developing countries.

Methods: This study comprises DHS data of 15 developing countries. A Meta-analysis, sub-group analysis, and meta-regression are used by the researcher to reach a valid conclusion keeping the study purposes in mind.

Results: This study has found that for the marriage age 18 and above, pooled OR is 0.47 [0.40; 0.56] which is statistically significant for 15 DHS data. A large amount of heterogeneity was found for meta-analysis with $\mathrm{I}^{2}=98 \%$. For Asian countries, the combined OR is $0.3828[0.27,0.54]$ on the contrary Non-Asian countries holds the pooled OR to be $0.4567[0.39,0.54]$. Also, the variation among different countries fertility performance for age at first marriage is largely explainable by the moderator variable per capita health expenditure (PCHE). PCHE alone is responsible for $57.14 \%$ of the heterogeneity among the overall explainable heterogeneity. Conclusion: In summary, our analysis highlights the effect of female age at first marriage on fertility in developing countries. This study explores the effective strategies to the developing countries that are suffering from high fertility.
\end{abstract}

\section{Introduction}

The reproductive performance and social status of women are largely explained by the age of their first marriage or cohabitation. In developing countries, high fertility is influenced by teenage pregnancy and early marriage. Early childbearing is influenced by early marriage and in most cases particularly in the developing world, the main purpose of marriage is to have children. ${ }^{1}$ Every year worldwide adolescents have more than 14 million births, and more than $90 \%$ of these occur in developing countries. ${ }^{2}$ Among all the birth of married women in many developing countries, about one-half and three quarters are found to be within two years of marriage. ${ }^{3}$ Taking children in an early age increases the fertility and the risks of mother and infant health including maternal mortality and morbidity as well as infant mortality, low birth weight and child stunting outcomes which is increased by poverty and inadequate access to maternal and child health service. ${ }^{4-6}$ For adolescents, younger than 18 the maternal death risk during childbirth is $2-4$ times higher than the women aged 20 or more. $^{7}$ It is estimated that 70,000 teenage girls die each year in developing countries from causes related to pregnancy and childbirth. And 1 million children of teenage mothers die before reaching their first birthday. ${ }^{8}$ Additionally, marriage during adolescence or previous to the age of 18 is regarded as a violation of human rights. ${ }^{9,10}$ This is interconnected with a range of adverse social outcomes, involving gender-based violence, lower educational attainment, and disempowerment of women, greater poverty and economic insecurity. ${ }^{11-16}$ Increasing the age at first marriage meaning the delayed marriage diminish the duration of time available for childbearing (particularly where no-marital childbearing is rare) which directly influences fertility rates. ${ }^{17}$ Delayed married women get enough opportunity to complete their education and focus to develop a career. These career interests persuade women to limit family size. ${ }^{18}$ Early marriage of women usually varies in the different part of the globe. We try to describe the differentials among countries that can either increase or decrease the trends of high fertility concerned with early marriage. Our main target is to obtain the fertility performance of women that is accounted for the age at first marriage in the developing part. (See Table 3)

\footnotetext{
* Corresponding author.

E-mail addresses: akhtarulstat@ku.ac.bd (Md. A. Islam), akashrahman32@gmail.com (A. Rahman).
} 
Table 1

Frequency table for the variable age at first marriage for selected developing countries.

\begin{tabular}{llll}
\hline \multirow{2}{*}{ Country } & Year of DHS & \multicolumn{2}{l}{ Age at First Marriage } \\
\cline { 3 - 4 } & & Below 18, n (\%) & 18 and above, n (\%) \\
& & $594(11.5)$ & $4578(88.5)$ \\
Albania & 2009 & $2557(35.9)$ & $4574(64.1)$ \\
Maldives & 2009 & $2568(30.5)$ & $5863(69.5)$ \\
Timor & 2010 & $5964(53.5)$ & $5180(46.5)$ \\
Cameroon & 2011 & $5706(58)$ & $4131(42)$ \\
Nepal & 2011 & $2349(20.7)$ & $9003(79.3)$ \\
Jordan & 2012 & $13592(76.1)$ & $4271(23.9)$ \\
Bangladesh & 2014 & $3795(29.4)$ & $9132(70.6)$ \\
Cambodia & 2014 & $5452(32.9)$ & $11128(67.1)$ \\
Peru & 2012 & $3930(53.3)$ & $3437(46.7)$ \\
Gambia & 2013 & $5694(42)$ & $7864(58)$ \\
Pakistan & 2013 & $5725(26.3)$ & $16037(73.7)$ \\
Egypt & 2014 & $8453(37.6)$ & $14051(62.4)$ \\
Kenya & 2014 & $1446(32.7)$ & $2974(67.3)$ \\
Lesotho & 2014 & $4112(42)$ & $5676(58)$ \\
Tanzania & 2016 & &
\end{tabular}

Table 2

Summary of meta-analysis for explaining high fertility with age at first marriage.

\begin{tabular}{llllll}
\hline Variable & Pooled OR & $95 \%$ CI & $\hat{\boldsymbol{Q}}$ & P-value & $\hat{\boldsymbol{I}}^{2}$ \\
\hline Age at first marriage & 0.46 & {$[0.39 ; 0.54]$} & 779.80 & $<0.01$ & $98 \%$ \\
\hline
\end{tabular}

\section{Methods}

\subsection{Sources of data}

The study uses data from the Demographic and Health Surveys (DHS). Considering the study objectives and availability of the variables
Table 3

Summary of subgroup analysis for explaining high fertility with age at first marriage.

\begin{tabular}{lllllll}
\hline Factor & Pooled OR & $95 \% \mathrm{CI}$ & $\mathrm{Q}$ & P-value & $\hat{\tau}^{2}$ & $\hat{\boldsymbol{I}}^{2}$ \\
\hline Asia & 0.3828 & {$[0.27,0.54]$} & 566.12 & $<0.0001$ & 0.2162 & $98.9 \%$ \\
Non-Asia & 0.5308 & {$[0.46,0.61]$} & 143.89 & $<0.0001$ & 0.0366 & $95.1 \%$ \\
Combined & 0.4567 & {$[0.39,0.54]$} & 779.80 & $<0.0001$ & 0.1106 & $98.6 \%$
\end{tabular}

$\hat{\tau}^{2}$ : Estimate of between-study variance.

required to conduct the study 15 DHS data have been chosen. The survey is based on a two-stage stratified sample of households where the entire country is divided into some non-overlapping enumeration areas that eventually edify the sampling frame. In the second stage of sampling a systematic sampling is appointed to pick out a fixed proportion of clusters and all the households within a cluster (enumeration area) is elected. Women aged 15-49 are selected and various personal and household information are retrieved from them. It is believed that the methodology used by DHS is standard and the quality of the questionnaire is never compromised to collect the data across countries. ${ }^{19}$ The outcome variable in the present study was fertility level, consisting of two categories (a) low fertility and (b) high fertility. The covariates used in the study include age at first marriage. Moderator variable per capita health expenditure per capita (current US\$) were considered to conduct meta-regression which is the sum of public and private health expenditures as a ratio of total population. It covers the health services (preventive and curative), contraception activities, nutrition activities, and emergency aid designated for health. ${ }_{-}^{20}$ We collected data for the corresponding year of the DHS countries from World Bank development indicators. ${ }^{20}$

\subsection{Meta-analysis}

To reach a conclusion about the fertility of developing countries

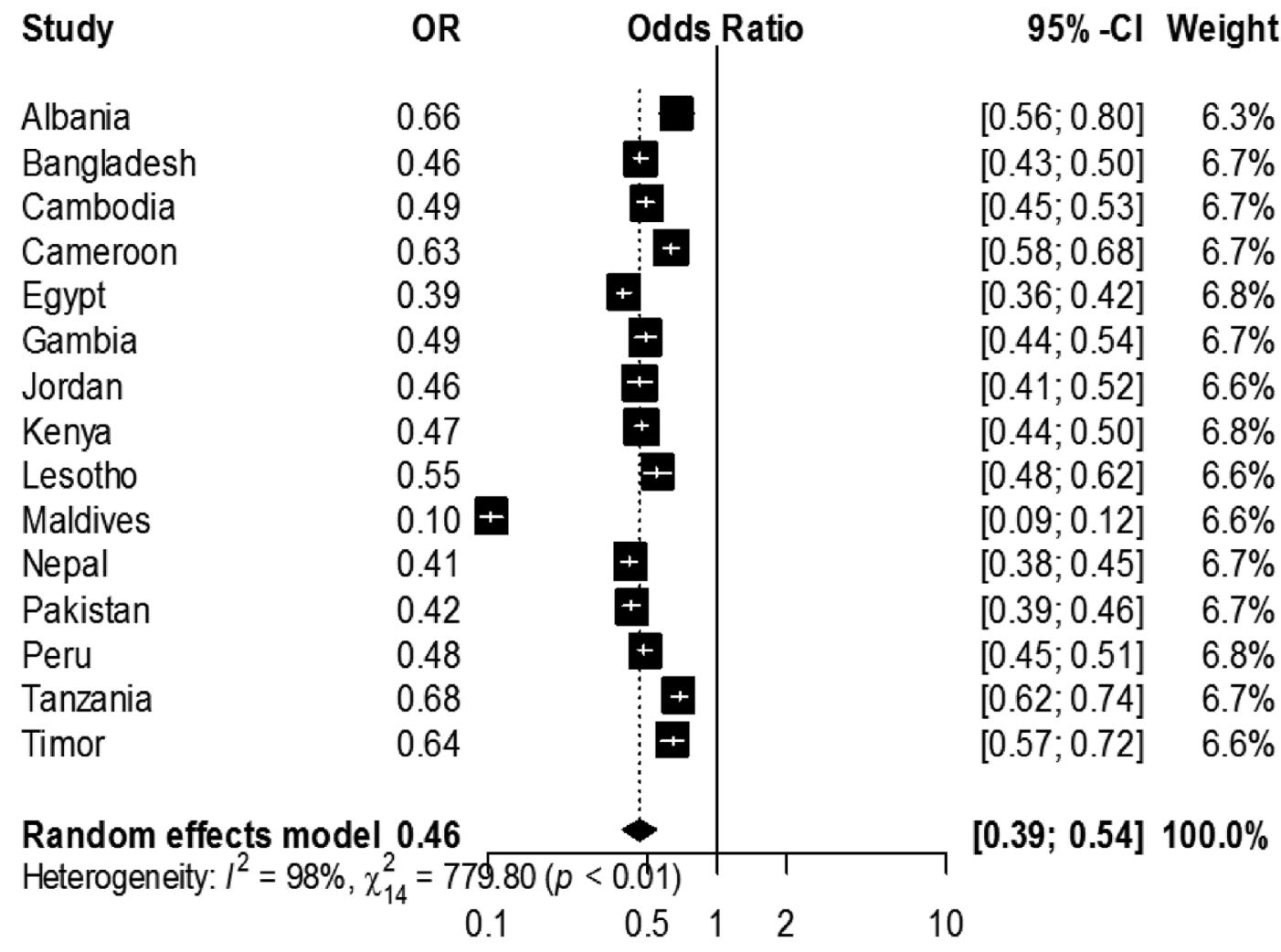

Fig. 1. Forest plot presenting odds ratios of high fertility for age at first marriage. 


\begin{tabular}{|c|c|c|c|c|}
\hline Study & OR & Odds Ratio & $95 \%-\mathrm{Cl}$ & Weight \\
\hline factor = "Asi & & & & \\
\hline Bangladesh & 0.46 & & {$[0.43 ; 0.50]$} & $6.7 \%$ \\
\hline Cambodia & 0.49 & & {$[0.45 ; 0.53]$} & $6.7 \%$ \\
\hline Jordan & 0.46 & & {$[0.41 ; 0.52]$} & $6.6 \%$ \\
\hline Maldives & $0.10+$ & & {$[0.09 ; 0.12]$} & $6.6 \%$ \\
\hline Nepal & 0.41 & & {$[0.38 ; 0.45]$} & $6.7 \%$ \\
\hline Pakistan & 0.42 & & {$[0.39 ; 0.46]$} & $6.7 \%$ \\
\hline Timor & 0.64 & & {$[0.57 ; 0.72]$} & $6.6 \%$ \\
\hline $\begin{array}{l}\text { Random effe } \\
\text { Heterogeneity: }\end{array}$ & $\begin{array}{l}\mathbf{0 . 3 8} \\
2=566.12 \\
6=56\end{array}$ & & {$[0.27 ; 0.54]$} & $46.7 \%$ \\
\hline factor $=$ "No & & & & \\
\hline Albania & 0.66 & & {$[0.56 ; 0.80]$} & $6.3 \%$ \\
\hline Cameroon & 0.63 & -1 & {$[0.58 ; 0.68]$} & $6.7 \%$ \\
\hline Egypt & 0.39 & & {$[0.36 ; 0.42]$} & $6.8 \%$ \\
\hline Gambia & 0.49 & & {$[0.44 ; 0.54]$} & $6.7 \%$ \\
\hline Kenya & 0.47 & & {$[0.44 ; 0.50]$} & $6.8 \%$ \\
\hline Lesotho & 0.55 & & {$[0.48 ; 0.62]$} & $6.6 \%$ \\
\hline Peru & 0.48 & & {$[0.45 ; 0.51]$} & $6.8 \%$ \\
\hline Tanzania & 0.68 & & {$[0.62 ; 0.74]$} & $6.7 \%$ \\
\hline Random effe & 0.53 & & {$[0.46 ; 0.61]$} & $53.3 \%$ \\
\hline Heterogeneity: & $=143.8$ & & & \\
\hline Random effe & 0.46 & & {$[0.39 ; 0.54]$} & $100.0 \%$ \\
\hline Heterogeneity: & $=779$. & $0.01)$ & & \\
\hline & 0.1 & 0.5 & & \\
\hline
\end{tabular}

Fig. 2. Forest plot for subgroup analysis for explaining high fertility with age at first marriage in different region.

Table 4

Summary of random effect meta-regression for the variable "Age at First Marriage" (without moderator).

\begin{tabular}{lllllll}
\hline$\hat{Q}$ & $d f$ & P-value & $\hat{I}^{2}$ & $\hat{\tau}^{2}$ & Estimate & P-value \\
\hline 332.2637 & 14 & $<0.0001$ & $97.08 \%$ & 0.0384 & -0.3161 & $<0.0001$ \\
\hline
\end{tabular}

$\hat{\tau}^{2}:$ Estimate of between-study variance.

Table 5

Summary of random effect meta-regression for the variable "Age at First Marriage" (with moderator PCHE).

\begin{tabular}{lllllll}
\hline$\hat{\tau}^{2}$ & $\hat{Q}$ & DF & P-value & coefficient & Estimate & P-value \\
\hline 0.0161 & \multirow{2}{*}{196.1251} & \multirow{2}{*}{13} & $<0.0001$ & Intercept & $\begin{array}{l}-0.2019 \\
-0.0008\end{array}$ & $\begin{array}{c}<0.0001 \\
0.0001\end{array}$ \\
& & & & PCHE & & \\
\hline
\end{tabular}

PCHE $=$ Per Capita Health Expenditure

accounted for age at first marriage, the researcher has used meta-analysis which is known as a method of summarizing the findings. Estimation of OR was possible using statistical software R for 15 DHS data. Due to the different circumstances of the countries, researchers went with the random effect meta-analysis. We have used the package 'meta' in $\mathrm{R}$ to perform the meta-analysis correctly.

\subsection{Subgroup analysis}

Subgroup analysis has been included for investigating some additional factors that can explain between countries heterogeneity.
Statistical software R with the help of package 'meta' subgroup analysis has taken part.

\subsection{Meta-regression}

In our meta-regression analysis, an individual country was used as the unit of analysis, and the outcomes were the logarithms of the ORs of fertility level in the 15 countries in which DHS were conducted. Metaregression was performed using statistical software $\mathrm{R}$ and 'metafor' package was utilized.

\section{Results}

Table 1 bears the characteristics of the sample that is utilized to make the study come to light. It is seen that, among all the countries, Bangladesh has most of the marriage before age 18. On the contrary, Albania manages the age at first marriage to be 18 and above for most of the cases.

Findings of meta-analysis using 15 different countries DHS data is displayed in Table 2. We considered age at first marriage 18 and above to be treatment group and age below 18 as our control group. For our treatment, we have found the estimated pooled OR is less than 1 for the event high fertility. This finding indicates if first marriage is done after 18 or at 18 it has 0.46 times less chance to contribute to high fertility than when marriage is done before 18 . Table 2 also consists of the $95 \%$ confidence interval for the pooled OR. From the pooled OR we can conclude that the result is statistically significant as there is no overlapping of the confidence interval with 1 . It is also found that a statistically significant heterogeneity test also exists with the observed 


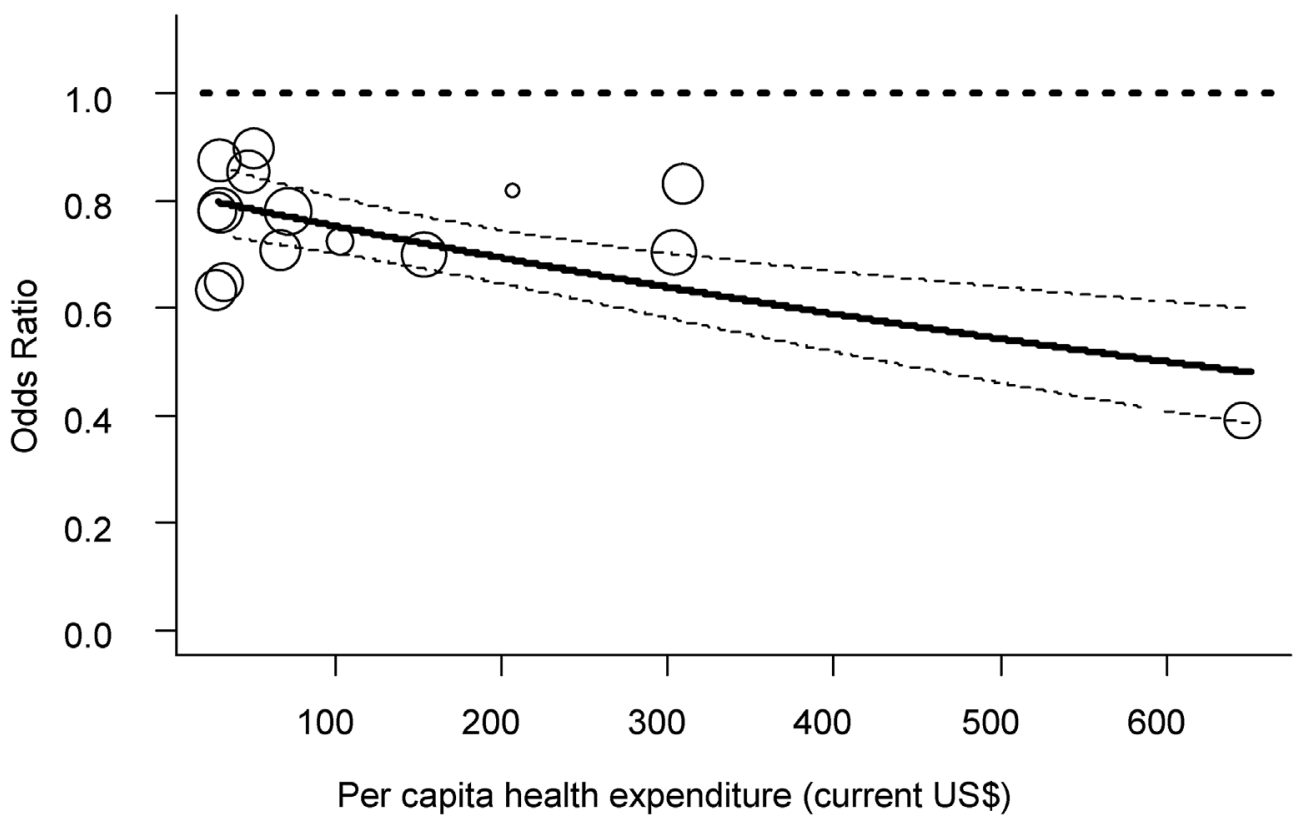

Fig. 3. Random-effect model meta-regression for the variable 'Age at First Marriage'.

sum of square $\hat{Q}^{2}=779.80$ (p-value $<0.01$ ), that is study do not share a common effect size. Percentage of total variation in ORs among countries for heterogeneity rather chance is very high with $I^{2}=98 \%$. These findings lead us to do subgroup analysis for explaining the amount of heterogeneity with respect to some factors. The findings of meta-analysis are better illustrated in a forest plot which helps to understand the scenario at an instance.

Fig. 1 illustrates that all the countries hold odds ratio below 1 indicating a negative impact in high fertility when first marriage age is 18 and above. Among them, Maldives is mostly affected by the age 18 and above as their age at first marriage compared to first marriage age below 18. The Maldives has the odds ratio of $0.10[0.09,0.12]$ which indicates $90 \%$ less chance of high fertility when marriage is done at age 18 and above compared to age below 18 . None of the countries confidence interval of odds ratio interacts with the line of no effect which ensures the statistical significance of the findings.

Table 3 and Fig. 2 illustrates that Asian countries have OR 0.38 $[0.27,0.54]$ times or $62 \%$ less chance to contribute in high fertility for first marriage age 18 and above than age below $18 . \hat{\tau}^{2}=0.2162$ indicates that the between study variance for Asian countries is $21 \%$. On the other hand, Non-Asian countries has $0.53[0.46,0.61]$ times or $47 \%$ less chance and $\hat{\tau}^{2}=0.0366$ indicates that the between study variance for Non- Asian countries is only $4 \%$. The combined odds ratio is 0.46 $[0.39,0.54] . \hat{\tau}^{2}=0.1106$ that means the between study variance or the variance of the true effect sizes for combined data is $11 \%$.

From Tables 4 and 5 we found that, the estimated total amount of heterogeneity is 0.0384 and percentage of the total amount of variability due to heterogeneity is $97.08 \%$. Furthermore, the test of heterogeneity is statistically significant since $\hat{Q}=332.2637$ with $D F=14$ and p-value $<0.0001$. The estimated value of the overall effect size is -0.3161 , which is also statistically significant since p-value $<0.0001$.

To explain the extra-heterogeneity, we have used different moderators such as per capita health expenditure (PCHE), Gross Domestic Product (GDP) and annual population growth (APG). Among three moderators, PCHE is capable to explain the heterogeneity significantly at $5 \%$ level of significance.

From the above table, we have found that the test for residual heterogeneity $(\hat{Q})=196.1251$ is still statistically significant at $5 \%$ level of significance with $d f=13$ and $\mathrm{p}$-value $=<0.0001$. But the estimated between-study variance dropped to 0.0161 from the previously estimated variance of 0.0384 . Thus $(0.0384-0.0161) / 0.0384=58.07 \%$ of the total amount of heterogeneity is accounted for per capita health expenditure alone. The estimated meta-regression equation can be written as:

$\log (O R)=-0.2019-(0.0008 \times P C H E)$

Findings from meta-regression have shown, moderator variable per capita health expenditure alone can explain $58.07 \%$ of the fertility behavior for variable age at first marriage.

In Fig. 3, each study is represented by a circle that shows the actual per capita health expenditure for that study. The size (specially the area) of each circle is proportional to that study's weight in the analysis. The thicker line shows the predicted values and the dotted line shows the $95 \%$ CI.

The meta-regression plot (bubble-plot) infer that the higher the health expenditure per capita lower the fertility performance.

\section{Discussion}

The analysis shows that the factor age at first marriage appeared to have a great influence on fertility behavior in developing countries. When age at first marriage is low such as before 18, it leads to increase in the number and children and overall fertility condition which are consistent with some earlier studies. ${ }^{21,22}$ The combined effect of Random effect model in meta-analysis has shown that women with age at first marriage 18 or above is 0.47 [0.40;0.56] times or $53 \%$ less chance to contribute in high fertility than the women with age at first marriage less than 18 in developing countries. Similar result found in south Asia that women who marry young have more children at the end of their reproductive careers because there is more time for them to increase their desired numbers of births and more opportunity for contraceptive failure to increase fertility. ${ }^{23}$ That means if we increase the age at first marriage the total fertility will decline. In particular, our results are very similar to the findings of various studies. ${ }^{24,25}$ In this analysis, we have found that the factor age at first marriage is more effective in Asian countries than the Non-Asian countries. Thus Asian countries are more sensitive to high fertility for 18 and above as first marriage age with a higher percentage of explainable variation $=98.9 \%$. In addition, when the per capita health expenditure in a developing country rises it assist with women's age 18 and above as first marriage for decline fertility. 


\section{Conclusion}

Available evidence suggests that age at first marriage is an important factor which implies lower fertility with rising age at first marriage. When age at first marriage is high the duration of marriage life is low, leads to fertility decline. This study suggests the policymaker and government of developing countries with over or high fertility take necessary steps to prohibit adolescent and early marriage for gaining the expected fertility. Policymakers of Asian developing countries suffering form over fertility should develop such situations to entertain age at first marriage to be 18 or above. Additionally we conclude that, per capita health expenditure of a country should be increased for countries with over or high fertility. This is an important factor that has impact on fertility performance and strong evidence to explain the heterogeneity in fertility behavior of developing countries.

\section{Ethical approval}

Not applicable.

\section{Funding}

This research did not receive any specific grant from funding agencies in the public, commercial, or not-for-profit sectors.

\section{Declaration of competing interest}

The authors have no conflicts of interest to declare.

\section{Acknowledgment}

We would also like to show our gratitude to Demographic and Health Surveys (DHS) Program and the World Bank for providing data access used in this research. Authors are debated to the Statistics Discipline, Khulna University for conducting this research activity successfully by making congenial work environment..

\section{References}

1. Ikamari L. The effect of education on the timing of marriage in Kenya. Demogr Res.
2005 Feb 23;12:1-28.

2. Alan Guttmacher Instituteed. Into a New World: Young Women's Sexual and Reproductive Lives. Alan Guttmacher Inst; 1998 May 1.

3. Wulf D, Singh S. Hopes and Realities: Closing the Gap between Women's Aspirations and Their Reproductive Experiences. The Institute; 1995.

4. Hobcraft J. Child spacing and child mortality. Proceedings of the. 1991; 1991:1157-1181.

5. Loaiza Sr E, Wong S. Marrying Too Young. End child marriage.

6. Amin S, Bajracharya A. Costs of Marriage-Mmarriage Transactions in the Developing World.

7. McCauley AP, Salter C, Kiragu K, Senderowitz J. Meeting the needs of young adults. Popul Rep J Fam Plann Progr. 1995 Oct(41):1-43.

8. Save the Children, State of the World's Mothers: 2004. Westport, CT, USA: Save the Children; 2004.

9. Singh S. Adolescent childbearing in developing countries: a global review. Stud Fam Plann. 1998 Jun 1:117-136.

10. UNICEF. Early Marriage a Harmful Traditional Practice a Statistical Exploration 2005. Unicef; 2005.

11. Singh S. Adolescent childbearing in developing countries: a global review. Stud Fam Plann. 1998 Jun 1:117-136.

12. Field E, Ambrus A. Early marriage, age of menarche, and female schooling attainment in Bangladesh. J Polit Econ. 2008 Oct;116(5):881-930.

13. Nguyen MC, Wodon Q. Global Trends in Child Marriage. Washington, DC: World Bank; 2012 Aug 6.

14. Nguyen MC, Wodon Q. Impact of Child Marriage on Literacy and Education Attainment in Africa. Washington, DC: UNICEF and UNESCO Statistics; 2014.

15. Wodon Q, Nguyen MC, Tsimpo C. Child marriage, education, and agency in Uganda. Fem Econ. 2016 Jan 2;22(1):54-79.

16. Raj A. When the Mother Is a Child: The Impact of Child Marriage on the Health and Human Rights of Girls.

17. Jensen R, Thornton R. Early female marriage in the developing world. Gend Dev. 2003 Jul 1;11(2):9-19.

18. Amin S. Female Education and Fertility in Bangladesh: The Influence of Marriage and the Family.

19. The DHS Program spatial data repository. [Online]. Available. www.dhsprogram. com; 2018 Accessed 23 January 2018.

20. The World Bank. World development indicators. [Online]. Available. www. worldbank.org/indicator; 2010.

21. Westoff CF. Trends in Marriage and Early Childbearing in Developing Countries.

22. Nahar MZ, Zahangir MS, Shafiqul Islam SM. Age at first marriage and its relation to fertility in Bangladesh. Chin J Popul Sci Resour Environ. 2013 Sep 1;11(3):227-235.

23. Marphatia AA, Ambale GS, Reid AM. Women's marriage age matters for public health: a review of the broader health and social implications in South Asia. Front Public Health. 2017 Oct 18;5:269.

24. Godha D, Hotchkiss D, Gage A. The Influence of Child Marriage on Fertility FertilityControl and Maternal Health Care Utilization: A Multi-Country Study from South Asia.

25. Singh BP, Maheshwari S. Age at first marriage and its impact on reproductive behaviour of women in Uttar Pradesh, India. J Stat Appl Probab. 2014 Jul 1;3(2):137. 